\title{
Article \\ The Physicochemical, Antioxidant, and Color Properties of Thin Films Based on Chitosan Modified by Different Phenolic Acids
}

\author{
Beata Kaczmarek-Szczepańska $^{1}$ (D) Lidia Zasada ${ }^{1}$ and Sylwia Grabska-Zielińska ${ }^{2, *(D)}$ \\ 1 Department of Biomaterials and Cosmetics Chemistry, Faculty of Chemistry, Nicolaus Copernicus University \\ in Toruń, Gagarin 7, 87-100 Toruń, Poland; beata.kaczmarek@umk.pl (B.K.-S.); 296559@stud.umk.pl (L.Z.) \\ 2 Department of Physical Chemistry and Polymer Physical Chemistry, Faculty of Chemistry, \\ Nicolaus Copernicus University in Torun, Gagarin 7, 87-100 Torun, Poland \\ * Correspondence: sylwia.gz@umk.pl
}

Citation: Kaczmarek-Szczepańska, B.; Zasada, L.; Grabska-Zielińska, S. The Physicochemical, Antioxidant, and Color Properties of Thin Films Based on Chitosan Modified by Different Phenolic Acids. Coatings 2022, 12, 126. https://doi.org/10.3390/ coatings 12020126

Academic Editor: Fengwei (David) Xie

Received: 12 December 2021

Accepted: 21 January 2022

Published: 23 January 2022

Publisher's Note: MDPI stays neutral with regard to jurisdictional claims in published maps and institutional affiliations.

Copyright: (C) 2022 by the authors. Licensee MDPI, Basel, Switzerland. This article is an open access article distributed under the terms and conditions of the Creative Commons Attribution (CC BY) license (https:// creativecommons.org/licenses/by/ $4.0 /)$.

\begin{abstract}
Chitosan-based films are promising for consideration as packaging materials. In this study, we modified the chitosan by phenolic acid addition, such as ferulic acid, caffeic acid, tannic acid, and gallic acid. The mechanical and thermal properties were studied, and the water vapor permeability rate was determined. Moreover, the antioxidant activity and film color were considered. The results showed that phenolic acids are effective cross-linkers for chitosan. The addition of phenolic acids improved the mechanical properties and decreased the roughness of surfaces. The enthalpy value was lower for films with phenolic acids than for pure chitosan. Chitosan with ferulic acid showed the highest antioxidant activity and water permeability value. Based on the obtained results, we determined that films obtained from the chitosan/ferulic acid mixture are the most promising for use as packaging material.
\end{abstract}

Keywords: chitosan; thin films; phenolic acids; antioxidant properties; films color; packaging materials

\section{Introduction}

The consumption of goods has an important environmental implications. Biopolymers are found in various applications in different aspects of human life, e.g., as dressing materials. They are non-toxic and biodegradable; thereby, they meet the requirements of green chemistry [1-3]. The important aspect is that the long-term existence of plastics and their resistance to degradation have created the need to search for new biodegradable products [4].

Biopolymers are naturally sourced compounds [5]. They may be modified by adding different compounds, which are called cross-linkers [6]. They interact with functional groups present in the polymeric chain, and, as a result, new bonds or interactions are formed. This improves the stability of materials obtained from biopolymers and allows for their application as packaging, coatings, or biocompatible layers [7].

Chitosan is an organic compound from the group of polysaccharides. It contains $(1,4)$ -linked 2-aminodeoxy- $\beta$-D-glucan, a derivative of a partially deacetylated chitin [8]. Chitosan is insoluble in water but easily dissolved in acidic aqueous solutions with a pH below 6.3 [8,9]. Chitosan is biocompatible, biodegradable, and non-toxic, and is one of the perfect carriers of minerals, vitamins, and other functional substances [8-10], which contributes to its use in production in packaging materials [11]. The use of chitosan in the production of packaging has an inherent antimicrobial activity compared with other polymers [9] and is a more environmentally friendly alternative to traditional packaging [12]. Packaging made of chitosan can have a great influence on the substances that would be placed in the shell of this biopolymer [10]. Such a biomaterial would increase the durability of products and keep them clean, which contributes to the safety of consumers [13]. 
An important aspect of green chemistry is the search for natural and non-toxic compounds which may act as cross-linkers. Phenolic acids have been considered in recent years as potentially safe and effective cross-linkers of biopolymers. Our previous studies confirmed that tannic acid is appropriate for use as a modifier of chitosan [14] and sodium alginate [15]. Additionally, we tested ferulic acid as a cross-linker of collagen [16].

The aim of the study was to compare various phenolic acids (ferulic acid, caffeic acid, tannic acid, gallic acid) in consideration as chitosan cross-linkers. The physicochemical properties of obtained materials in thin film formation were studied, such as thermal and mechanical properties, surface free energy and water vapor permeation rate measurement, antioxidant activity, and film color.

\section{Materials and Methods}

\subsection{Chemicals}

Chitosan (CTS) was supplied from Sigma Aldrich (Poznań, Poland). Tannic acid (TA), ferulic acid (FA), and caffeic acid (CA) were purchased form ROTH Company (Karlsruhe, Germany). Gallic acid (GA) was supplied from POCh (Gliwice, Poland). The deacetylation degree (DD, \%) of chitosan was $78 \%$, and the molecular weight was $1.8 \times 10^{6} \mathrm{Da}$.

\subsection{Fabrication of Chitosan/Phenolic Acid Films}

Chitosan and phenolic acids were dissolved in $0.1 \mathrm{M}$ acetic acid, separately, at a concentration of $1 \%$. Phenolic acid solutions at $1 \%$ concentration were heated in the heating mantle (DanLab, Białystok, Poland) to completely dissolve compounds. To the chitosan solution, a phenolic acid solution was added in the weight ratio $10 \%$. The mixture was stirred for $1 \mathrm{~h}$ by a magnetic stirrer (ChemLand, Stargard Szczeciński, Poland). Then, the mixture was placed on the plastic holder $(40 \mathrm{~mL}$ per $10 \mathrm{~cm} \times 10 \mathrm{~cm})$. Thin films were obtained by solvent evaporation method in room conditions (temperature and humidity) [15].

\subsection{Mechanical Testing}

The mechanical testing was carried out with the use of a testing machine (Shimadzu EZ-Test EZ-SX, Kyoto, Japan). Samples with known thickness were inserted between 2 handles and stretched with a velocity of $5 \mathrm{~mm} / \mathrm{min}$ [15]. Young's modulus was calculated from the slope of the stress-strain curve in the linear region with the use of the Trapezium $X$ Texture program (Kyoto, Japan). Each measurement was carried out with 10 repetitions.

\subsection{Roughness}

The topography of the obtained films was observed by using the scanning probe microscope equipped with a Nanoscope IIIa controller (Digital Instruments, Santa Barbara, CA, USA) operating in the tapping mode (room conditions; a scan rate of $1.97 \mathrm{~Hz}$; a spring constant $2-10 \mathrm{~N} / \mathrm{m}$ of silicon tips) [17]. The roughness of the surface of the film was calculated from $1 \mu \mathrm{m} \times 1 \mu \mathrm{m}$ scanned area using Nanoscope software (Billerica, MA, USA).

\subsection{Differential Scanning Calorimetry (DSC)}

Differential scanning calorimetry measurements were made by DSC equipment (NETZSCH Phoenix DSC 204 F1, Selb, Germany). The heating rate was $10^{\circ} \mathrm{C} / \mathrm{min}$, from 20 to $250{ }^{\circ} \mathrm{C}$ in a nitrogen atmosphere with the gas flow $40 \mathrm{~mL} / \mathrm{min}$. The weight of samples placed in the aluminum measuring pans was $1.0-1.5 \mathrm{mg}$ [18].

\subsection{Water Vapor Permeation Rate (WVPR)}

The WVPR of films was investigated. A known weight of dried anhydrous calcium chloride $\left(m_{0}\right)$ as a desiccant was placed into the plastic container with $5 \mathrm{~cm}$ diameter. The desiccant was prepared by drying it at $105^{\circ} \mathrm{C}$ for $24 \mathrm{~h}$ before use. Films were placed on top of the containers and sealed tightly. Each kind of sample was tested in duplicate. After $24 \mathrm{~h}$, the samples were weighed $\left(m_{t}\right)$, and the weight change was determined (Equation (1)) [15], as follows: 


$$
\text { the percentage weight gain of } \mathrm{CaCl}_{2}=\frac{m_{t}-m_{0}}{m_{0}} \times 100 \%
$$

The water permeability was recalculated to the $\mathrm{mg} / \mathrm{cm}^{2} / \mathrm{h}$ units.

\subsection{DPPH Radical Scavenging Assay}

Antioxidant properties of films were determined using the DPPH reagent (2,2-Diphenyl1-picrylhydrazyl, free radical, 95\%; Alfa Aesar, Lancashire, UK) [19]. Samples $(1 \mathrm{~cm} \times 1 \mathrm{~cm})$ of each film were placed in a 12-well plate and filled with $2 \mathrm{~mL}$ of a DPPH solution $(250 \mu \mathrm{M}$ solution in methyl alcohol). They were left without exposure to light for $1 \mathrm{~h}$. The tested samples were replicated three times. The control sample was a DPPH solution left on the plate without contact with the films. After incubation, a spectrophotometric measurement was made at $517 \mathrm{~nm}$ (UV-1800, Shimadzu, Reinach, Switzerland). The antioxidant activity was calculated with the following formula (Equation (2)):

$$
R S A \%=\frac{A b s_{D P P H}-A b s_{P B}}{A b s_{D P P H}} \times 100
$$

where:

$A b s_{D P P H}$ is the absorbance of the DPPH solution without contact with the materials.

$A b s_{D P P H}$ is the absorbance of the DPPH solution after contact with the material being tested.

\subsection{Film Color}

Color variations of each sample were measured using a colorimeter (Corneometer CL 400, Courage + Khazaka electronic GmbH, Cologne, Germany). The color parameter $L$ (which describes the sample lightness), a (along the $x$ axis from red $(+)$ to green $(-)$ ), and $\mathrm{b}$ (along the $y$ axis from yellow $(+)$ to blue $(-)$ ) were evaluated $[20,21]$. The total color difference $(\Delta E)$ and whiteness index $(W I)$ were then calculated using Equations (3) and (4), as follows:

$$
\begin{gathered}
\Delta E=\left(\Delta L^{2}+\Delta a^{2}+\Delta b^{2}\right)^{0.5} \\
W I=100-\left((100-L)^{2}+a^{2}+b^{2}\right)^{0.5}
\end{gathered}
$$

where:

$\Delta L=L-L_{0} ; \Delta a=a-a_{0} ; \Delta b=b-b_{0} ;$

$L$ - the component describing lightness;

$a$-represents the color ranging from green $(-a)$ to red $(+a)$;

$b$-represents the color ranging from blue $(-b)$ to yellow $(+b)$;

$L_{0} ; a_{0} ; b_{0}$-color values for the white background, $L_{0}$ (lightness), $a_{0}$ (redness / greenness), and $b_{0}$ (yellowness/blueness).

\subsection{Statistics}

Data of mechanical testing $(n=10)$, roughness parameters, RSA $(n=3)$ results, and color characteristics were expressed as polled means \pm standard deviation (S.D.). Statistically significant differences between results of mechanical testing were determined by the univariate analysis of variance (ANOVA) using GraphPad Prism 8.0.1.244 software (La Jolla, CA, USA).

\section{Results}

\subsection{Mechanical Testing}

The mechanical parameters of the thin films are shown in Figure 1. The thickness of the studied samples was in the range $0.021 \pm 0.003 \mathrm{~mm}$. The addition of phenolic acids improved the mechanical properties of the chitosan-based films. The highest Young's modulus was noted for the chitosan/ferulic acid film and the highest maximum tensile strength was noted for the chitosan/caffeic acid film. Young modulus for the obtained 
films was in the range 1000-1500 MPa and maximum tensile strength was in the range 40-50 MPa.
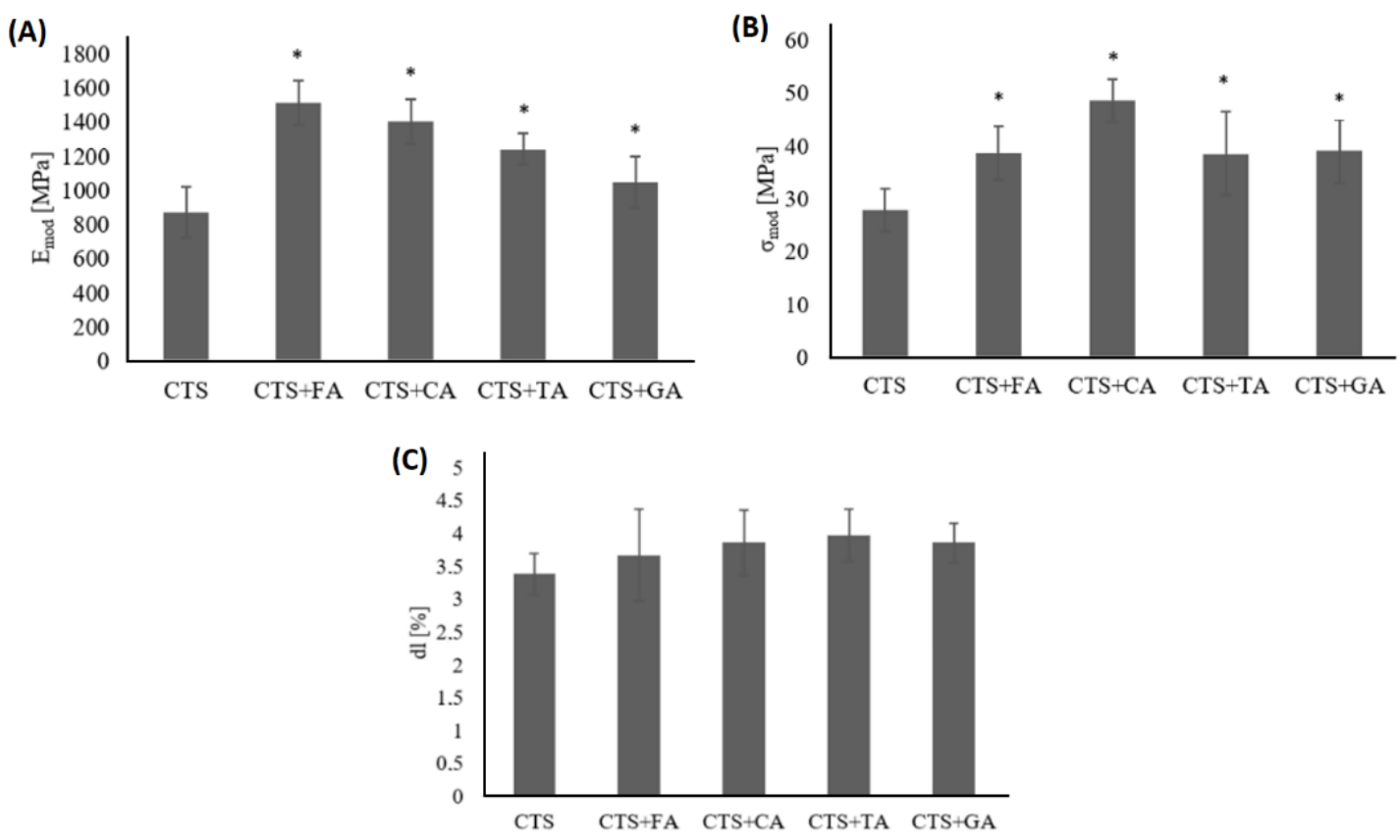

Figure 1. The mechanical parameters, such as: (A) Young modulus ( $\left.E_{\text {mod }}\right),($ B $)$ maximum tensile strength $\left(\sigma_{\mathrm{mod}}\right)$ and $(\mathbf{C})$ elongation at break $(\mathrm{dl})$ determined for each type of sample (* significantly different from control-CTS $-p<0.05)$.

\subsection{Roughness}

The results in Table 1 show the influence of phenolic acid on the roughness of the films' surfaces. The addition of each phenolic acid to the chitosan results in the reduction of $\mathrm{Ra}$ and $\mathrm{Rq}$ parameters. The positively charged chitosan interacts with phenolic acids, and the organization of the polymeric chain is changed. Less functional groups are free as they interact with phenolic acids by strong hydrogen bonds. Thereby, the decrease of the roughness parameters is observed.

Table 1. Roughness parameters ( $\mathrm{Ra}$ and $\mathrm{Rq})$ of films $(n=5$; * significantly different from CTS$p<0.05)$.

\begin{tabular}{ccc}
\hline Specimen & Ra [nm] & Rq [nm] \\
\hline CTS & $72.4 \pm 0.30$ & $81.5 \pm 0.52$ \\
CTS + FA & $57.9 \pm 0.40^{*}$ & $71.9 \pm 0.37^{*}$ \\
CTS + CA & $24.1 \pm 0.34^{*}$ & $29.7 \pm 0.31^{*}$ \\
CTS + TA & $21.7 \pm 0.42^{*}$ & $26.7 \pm 0.42^{*}$ \\
CTS + GA & $34.1 \pm 0.37^{*}$ & $43.2 \pm 0.52^{*}$ \\
\hline
\end{tabular}

Ra-mean arithmetic deviation of the profile from the mean line; Rq-mean square deviation of surface roughness.

\subsection{Differential Scanning Calorimetry (DSC)}

Differential scanning calorimetry was used to determine the maximum temperatures of the process $(\mathrm{T})$ and the enthalpy of the processes $(\Delta \mathrm{H})$, which occurred during the heating of the samples. The measurement results are shown in Table 2. The first peak is associated with the presence of water in the material and its release during heating. The highest content of water was found for the chitosan film. The addition of phenolic acids decreased the enthalpy value; this is a result of hydrogen bonds present between chitosan and phenolic acids, which decrease the amount of water bonded to the chitosan. The maximum temperature of the second peak was higher for materials modified by the 
addition of phenolic acids. The enthalpy of the second peak and the first peak was similarly decreased. Thereby, the interactions between chitosan and phenolic acids result in the improvement of thermal properties.

Table 2. The maximum temperature of the process $(\mathrm{T})$ and enthalpy of the processes $(\Delta \mathrm{H})$ measured during the samples heating by differential scanning calorimetry $\left({ }^{*}\right.$ significantly different from CTS$p<0.05)$.

\begin{tabular}{ccccc}
\hline Specimen & $\mathbf{T} \mathbf{1}\left[{ }^{\circ} \mathbf{C}\right]$ & $\mathbf{\Delta H} \mathbf{1}[\mathbf{m W} / \mathbf{m g}]$ & $\mathbf{T} \mathbf{2}\left[{ }^{\circ} \mathbf{C}\right]$ & $\Delta \mathbf{H} \mathbf{2}[\mathbf{m W} / \mathbf{m g}]$ \\
\hline CTS & 77.9 & 1.342 & 196.0 & 0.3357 \\
CTS + FA & $68.6^{*}$ & 1.238 & $204.7^{*}$ & $0.2747^{*}$ \\
CTS + CA & $71.2^{*}$ & $0.993^{*}$ & 200.8 & $0.2188^{*}$ \\
CTS + TA & $68.3^{*}$ & $1.050^{*}$ & 200.4 & $0.1376^{*}$ \\
CTS + GA & $69.3^{*}$ & $1.174^{*}$ & $201.8^{*}$ & $0.3104^{*}$ \\
\hline
\end{tabular}

\subsection{Water Vapor Permeation Rate (WVPR)}

The water vapor permeation rate is an important factor for the materials to be considered as packaging. The water permeability across the materials improves the regeneration processes. The WVPR may be studied by the determination of calcium chloride grains weight change which is proportional to WVPR (Figure 2). The addition of phenolic acids improves the water permeability compared with pure chitosan-based films. The highest calcium chloride weight change was observed for chitosan modified by ferulic acid. The recalculated values of WVPR are listed in Table 3. It may be observed that, consistent with the results of calcium chloride weight change, the WVPR is higher for the chitosan-based films modified by phenolic acids than for pure chitosan. It may suggest that the modification of chitosan by phenolic acid addition allows materials with improved water permeability properties to be obtained.

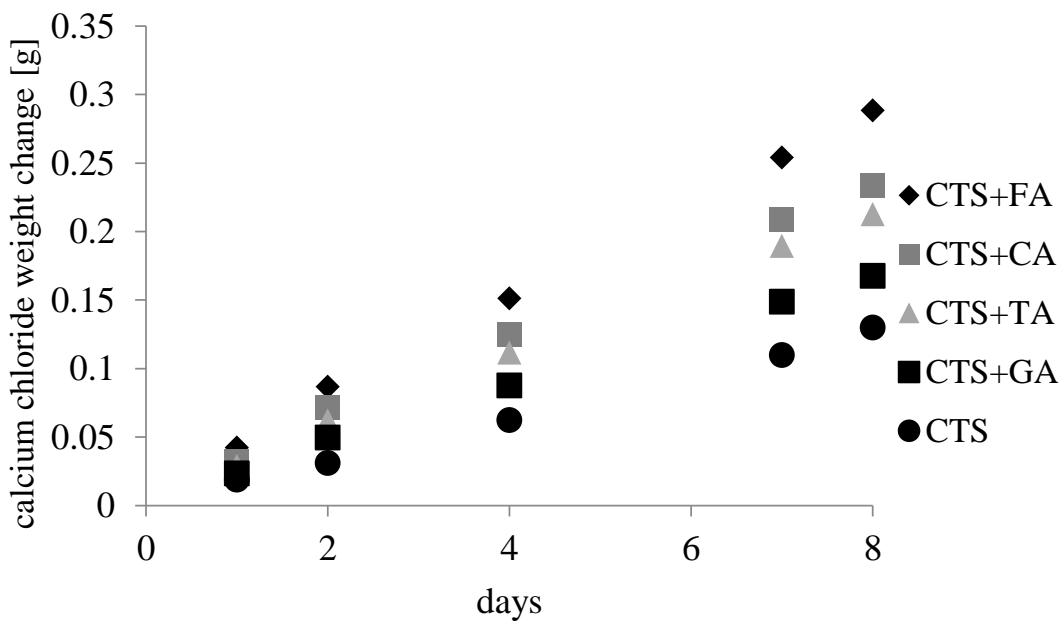

Figure 2. The weight change of calcium chloride grains after $1,2,4,7$, and 8 days $\left(37^{\circ} \mathrm{C}\right)$ for samples based on chitosan modified by phenolic acids.

Table 3. The water permeability recalculated to $\mathrm{mg} / \mathrm{cm}^{2} / \mathrm{h}$ units ( ${ }^{*}$ significantly different from CTS $-p<0.05)$.

\begin{tabular}{cc}
\hline Specimen & WVPR $\left[\mathrm{mg} / \mathrm{cm}^{2} / \mathrm{h}\right]$ \\
\hline CTS & 4.04 \\
CTS + FA & $9.06^{*}$ \\
CTS + CA & $6.82^{*}$ \\
CTS + TA & $6.18^{*}$ \\
CTS + GA & $5.04^{*}$ \\
\hline
\end{tabular}




\subsection{DPPH Radical Scavenging Assay}

There is a need to search for materials with antioxidant activity to improve the wound healing processes. The antioxidant activity as RSA\% value for chitosan films modified by different phenolic acids is listed in Table 4. Phenolic acids act as chitosan cross-linkers. However, they also have active properties. It may be assumed that unmodified chitosanbased films show weaker antioxidant activity than with the presence of phenolic acids. The highest RSA value was noticed for chitosan with ferulic acid addition.

Table 4. Antioxidant activity (RSA\%) of chitosan-based films modified by phenolic acids ( ${ }^{*}$ significantly different from CTS $-p<0.05)$.

\begin{tabular}{cc}
\hline Specimen & RSA [\%] \\
\hline CTS & $17.21 \pm 1.03$ \\
CTS + FA & $89.83 \pm 2.10^{*}$ \\
CTS + CA & $30.84 \pm 2.20^{*}$ \\
CTS + TA & $17.21 \pm 1.03$ \\
CTS + GA & $56.03 \pm 2.15^{*}$ \\
\hline
\end{tabular}

\subsection{Film Color}

The color values for chitosan/phenolic acids films are shown in Table 5. $L^{*}$ indicates the brightness of films, whereas $a^{*}$ indicates the greenness/redness, and $b^{*}$ indicates the blueness/yellowness of the tested films. The addition of phenolic acids increases the $b^{*}$ parameter. The addition of phenolic acids increased the $\Delta E$ and decreased WI values.

Table 5. The color values $\left(L^{*} a^{*} b^{*}\right)$, a total difference of color value $(\Delta E)$, and whiteness index $(W I)$ of films based on chitosan modified by phenolic acids. $\left({ }^{*}\right.$ significantly different from CTS $\left.-p<0.05\right)$.

\begin{tabular}{cccccc}
\hline Specimen & $\boldsymbol{L}^{*}$ & $\boldsymbol{a}^{*}$ & $\boldsymbol{b}^{*}$ & $\boldsymbol{\Delta} \boldsymbol{W}$ & $\boldsymbol{W I}$ \\
\hline CTS & $94.09 \pm 0.37$ & $-1.65 \pm 0.23$ & $2.03 \pm 0.45$ & $3.91 \pm 0.04$ & $93.54 \pm 0.09$ \\
CTS + FA & $92.74 \pm 0.10^{*}$ & $-1.66 \pm 0.21$ & $3.79 \pm 0.09^{*}$ & $4.34 \pm 0.08^{*}$ & $91.64 \pm 0.11^{*}$ \\
CTS + CA & $93.06 \pm 1.18$ & $-1.05 \pm 0.16^{*}$ & $3.23 \pm 2.16^{*}$ & $4.02 \pm 0.11^{*}$ & $92.27 \pm 0.15^{*}$ \\
CTS + TA & $91.76 \pm 2.05$ & $-1.81 \pm 0.40^{*}$ & $4.56 \pm 0.60^{*}$ & $4.77 \pm 0.07 *$ & $90.41 \pm 0.08^{*}$ \\
CTS + GA & $89.98 \pm 1.40^{*}$ & $-1.98 \pm 0.13^{*}$ & $10.40 \pm 0.40 *$ & $10.54 \pm 0.13^{*}$ & $85.43 \pm 0.10^{*}$ \\
\hline
\end{tabular}

\section{Discussion}

The physicochemical properties of films are important in their consideration as packaging materials. Natural polymers are promising substrates for biomedical products obtainment [22]. In our studies, we modified chitosan by the addition of natural cross-linkers, which are phenolic acids, such as ferulic acid, caffeic acid, tannic acid, and gallic acid. The obtained mechanical parameters for the chitosan/phenolic acid films are higher than for pure chitosan. This suggests that the presence of phenolic acids improved the mechanical properties. A similar correlation was reported by Liu et al. for chitosan-based films [23]. Zarandona et al. reported that gallic acid addition improved the mechanical properties of materials based on chitosan through physical interactions, such as hydrogen bonds and electrostatic and hydrophobic forces [24]. Additionally, the chitosan films grafted by ferulic acid and caffeic acid showed better mechanical properties than pure chitosan [25]. This provides evidence that phenolic acids, acting as cross-linker, improve chitosan-based films' mechanical properties.

The roughness of the films' surfaces depends on the material composition. This is important to consider, as the topography of a packaging material may influence food adhesion or biofilm formation. Ringus and Moraru [26] compared the roughness of different packaging materials. The Ra and Rq for LDPE were determined as $44 \mathrm{~nm}$ and $59 \mathrm{~nm}$, respectively, and $60 \mathrm{~nm}$ and $83 \mathrm{~nm}$ for HDPE, respectively. Roughness determined for chitosan films was similar to that for LDPE and HDPE. For instance, the Ra of PVA film was determined as $10.05 \mathrm{~nm}$ [27]. The results obtained in the present study showed that 
the addition of phenolic acids decreases the roughness parameters. Similar results were obtained by us in the study of UVC light influence on the films' surfaces parameters [28].

Thermal properties are important to be considered to determine the possibility for thermal treatment, e.g., sterilization. The addition of phenolic acids improved the thermal resistance of materials. Similar results were obtained by Sun et al., where the modification of chitosan films by the addition of young apple polyphenols resulted in the improvement of thermal properties [29]. It was found by Can et al. that thermal transitions around $200{ }^{\circ} \mathrm{C}$ are ascribed to complex processes, including the dehydration of the saccharide rings, the depolymerization of the acetylated and deacetylated units, and the galactose group of the polymer [30]. In our studies, the addition of phenolic acids shifted the maximum temperature of the second peak for a few degrees. The thermal stability was not remarkably affected by the kind of added phenolic acid. A similar conclusion had been made in the study of Yong et al. [25].

The water permeability rate (WVPR) is one of the key parameters which allows a consideration of the material as being safe for wound healing [25]. The modification of chitosan films by phenolic acid addition results in an increase in WVPR, as phenolic acids bear many hydroxylic groups, which are able to bind water [31]. Similar results were obtained by Li et al., with the addition of ferulic acid to chitosan/alginate mixture [32].

Antioxidant compounds present in packaging material can serve as a carrier to keep high concentrations of preservatives. Thereby, the materials showing antioxidation activity are interesting for investigation. A DPPH radical scavenging assay showed that, after the addition of phenolic acids, the antioxidant properties increased. Such correlation was reported by other researchers [33-36]. The highest antioxidant activity showed ferulic acid. A similar conclusion was made by Kikuzaki et al. [37] and Cheng et al. [38], where the chitosan films modified by phenolic acids showed antioxidant activity.

The color quality is crucial as it may influence the appearance of films, which affects the acceptance of foods by consumers. Film color may influence customer choices. In our studies, we assumed that phenolic acids addition did not significantly change films' color $(\Delta E<5)$. Only for chitosan/gallic acid films is the change clear. The color of chitosan grafted by gallic acid was named by Liu et al. as dark yellow-this was confirmed in our studies [39]. The $\Delta \mathrm{E}$ above 5 for films of chitosan grafted by caffeic acid and ferulic acid was reported by Yong et al. [25].

\section{Conclusions}

Our studies have confirmed that phenolic acids are effective cross-linkers of chitosanbased materials. Their addition results in the improvement of mechanical and thermal properties, while also providing antioxidant activity. We compared four phenolic acidsferulic acid, caffeic acid, tannic acid, and gallic acid. The most promising results were obtained for the chitosan-based films modified by ferulic acid addition. CTS/FA films showed the highest roughness, WVPR values, and antioxidant activity. Film based on chitosan, modified by ferulic acid, is promising for its potential application as packaging.

Author Contributions: Conceptualization, B.K.-S. and S.G.-Z.; methodology, B.K.-S. and S.G.-Z.; software, B.K.-S.; formal analysis, L.Z.; investigation, B.K.-S.; resources, B.K.-S.; data curation, L.Z.; writing-original draft preparation, B.K.-S.; writing-review and editing, S.G.-Z.; visualization, B.K.-S. and S.G.-Z.; supervision, B.K.-S.; project administration, B.K.-S.; funding acquisition, B.K.-S. All authors have read and agreed to the published version of the manuscript.

Funding: This research was funded by Nicolaus Copernicus University in Torun (282/2021 IDUB (B.K.S.)).

Institutional Review Board Statement: Not applicable.

Informed Consent Statement: Not applicable.

Data Availability Statement: The raw/processed data required to reproduce these findings cannot be shared at this time as the data also forms part of an ongoing study. 
Conflicts of Interest: The authors declare no conflict of interest.

\section{References}

1. Reddy, M.S.B.; Ponnamma, D.; Choudhary, R.; Sadasivuni, K.K. A comparative review of natural and synthetic biopolymer composite scaffolds. Polymers 2011, 13, 1105. [CrossRef]

2. Zhong, Y.; Godwin, P.; Jin, Y.; Xiao, H. Biodegradable polymers and green-based antimicrobial packaging materials: A mini-review. Adv. Ind. Eng. Polym. Res. 2020, 2, 27-35. [CrossRef]

3. Song, R.; Murphy, M.; Li, C.; Ting, K.; Soo, C.; Zheng, Z. Current development of biodegradable polymeric materials for biomedical applications. Drug Des. Devel. Ther. 2008, 12,3117-3145. [CrossRef] [PubMed]

4. Folino, A.; Karageorgiou, A.; Calabro, P.S.; Komilis, D. Biodegradation of wasted bioplastics in natural and industrial environments: A review. Sustainability 2020, 12, 6030. [CrossRef]

5. Bahrami, R.; Zibaei, R.; Hashami, Z.; Hasanvand, S.; Garavand, F.; Rouhi, M.; Jafari, S.M.; Mohammadi, R. Modification and improvement of biodegradable packaging films by cold plasma; a critical review. Crit. Rev. Food Sci. Nutr. 2020, 1-15. [CrossRef] [PubMed]

6. Garavand, F.; Rouhi, M.; Razavi, S.H.; Cacciotti, I.; Mohammadi, R. Improving the integrity of natural biopolymer films used in food packaging by crosslinking approach: A review. Int. J. Biol. Macromol. 2017, 104, 687-707. [CrossRef] [PubMed]

7. Singh, P.; Baisthakur, P.; Yemul, O.S. Synthesis, characterization and application of crosslinked alginate as green packaging material. Heliyon 2020, 6, e03026. [CrossRef] [PubMed]

8. Zhang, X.; Ismail, B.B.; Cheng, H.; Jin, T.Z.; Qian, M.; Arabi, S.A.; Liu, D.; Guo, M. Emerging chitosan-essential oil films and coatings for food preservation-A review of advances and applications. Carbohydr. Polym. 2021, 273, 118616. [CrossRef] [PubMed]

9. Salgado-Cruz, M.D.L.P.; Salgado-Cruz, J.; García-Hernández, A.B.; Calderón-Domínguez, G.; Gómez-Viquez, H.; Oliver-Espinoza, R.; Fernández-Martínez, M.C.; Yáñez-Fernández, J. Chitosan as a Coating for Biocontrol in Postharvest Products: A Bibliometric Review. Membranes 2021, 11, 421. [CrossRef]

10. Ortega-Ortiz, H.; Gutierrez-Rodriguez, B.; Cadenas-Pliego, G.; Jimenez, L.I. Antibacterial Activity of Chitosan and the Interpolyelectrolyte Complexes of Poly(acrylic acid)-Chitosan, Braz. Arch. Biol. Technol. 2010, 53, 623-628. [CrossRef]

11. Garavand, F.; Cacciotti, I.; Vahedikia, N.; Rehman, A.; Tarhan, Ö.; Akbari-Alavijeh, S.; Shaddel, R.; Rashidinejad, A.; Nejatian, M.; Jafarzadeh, S.; et al. A comprehensive review on the nanocomposites loaded with chitosan nanoparticles for food packaging. Crit. Rev. Food Sci. Nutr. 2020, 1-34. [CrossRef] [PubMed]

12. Hadidi, M.; Jafarzadeh, S.; Forough, M.; Garavand, F.; Alizadeh, S.; Salehabadi, A.; Khaneghah, A.M.; Jafari, S.M. Plant proteinbased food packaging films; recent advances in fabrication, characterization, and applications. Trends Food Sci. Technol. 2020, 20, 154-173. [CrossRef]

13. Kritchenkov, A.S.; Egorov, A.R.; Kurasova, M.N.; Volkova, O.V.; Meledina, T.V.; Lipkan, N.A.; Tskhovrebov, A.G.; Kurliuk, A.V.; Shakola, T.V.; Dysin, A.P.; et al. Novel non-toxic high efficient antibacterial azido chitosan derivatives with potential application in food coatings. Food Chem. 2019, 301, 125247. [CrossRef] [PubMed]

14. Hosseinnejad, M.; Jafari, S.M. Evaluation of different factors affecting antimicrobial properties of chitosan. Int. J. Biol. Macromol. 2016, 85, 467-475. [CrossRef] [PubMed]

15. Kaczmarek, B.; Nadolna, K.; Owczarek, A.; Michalska-Sionkowska, M.; Sionkowska, A. The characterization of thin films based on chitosan and tannic acid mixture for potential applications as wound dressings. Polym. Test. 2019, 78, 106007. [CrossRef]

16. Kaczmarek, B. Improving sodium alginate films properties by phenolic acid addition. Materials 2020, 13, 2895. [CrossRef]

17. Kaczmarek, B.; Lewandowska, K.; Sionkowska, A. Modification of collagen properties with ferulic acid. Materials 2020, 13, 3419. [CrossRef]

18. Olewnik-Kruszkowska, E.; Gierszewska, M.; Grabska-Zielińska, S.; Skopińska-Wiśniewska, J.; Jakubowska, E. Examining the Impact of Squaric Acid as a Crosslinking Agent on the Properties of Chitosan-Based Films. Int. J. Mol. Sci. 2021, $22,3329$. [CrossRef]

19. Kaczmarek, B.; Sosik, A.; Małkowska, A.; Zasada, L.; Michalska-Sionkowska, M. The Study of Physicochemical Properties and Blood Compatibility of Sodium Alginate-Based Materials via Tannic Acid Addition. Materials 2021, 14, 4905. [CrossRef]

20. Ballester-Costa, C.; Sendra, E.; Fernandez-Lopez, J.; Viuda-Martos, M. Evaluation of the antibacterial and antioxidant activities of chitosan edible films incorporated with organic essential oils obtained from four Thymus species. J. Food Sci. Technol. 2016, 53, 3374-3379. [CrossRef]

21. Prus-Walendziak, W.; Kozłowska, J. Design of sodium alginate/gelatin-based emulsion film fused with polylactide microparticles charged with plant extract. Materials 2021, 14, 745. [CrossRef] [PubMed]

22. Suresh, S.; Pushparaj, C.; Subramani, R. Recent development in preparation of food packaging films using biopolymers. Food Res. 2021, 5, 12-22. [CrossRef]

23. Grabska-Zielińska, S.; Gierszewska, M.; Olewnik-Kruszkowska, E.; Bouaziz, M. Polylactide Films with the Addition of Olive Leaf Extract-Physico-Chemical Characterization. Materials 2021, 14, 7623. [CrossRef] [PubMed]

24. Liu, W.; Xie, J.; Li, L.; Xue, B.; Li, X.; Gan, J.; Shao, Z.; Sun, T. Properties of phenolic acid-chitosan composite films and preservative effect on Penaeus vannamei. J. Mol. Str. 2021, 1239, 130531. [CrossRef]

25. Yong, H.; Liu, Y.; Yun, D.; Zong, S.; Jin, C.; Liu, J. Chitosan Films Functionalized with Different Hydroxycinnamic Acids: Preparation, Characterization and Application for Pork Preservation. Foods 2021, 10, 536. [CrossRef] [PubMed] 
26. Zarandona, I.; Puertas, A.I.; Dueñas, M.T.; Guerrero, P.; de la Caba, K. Assessment of active chitosan films incorporated with gallic acid. Food Hydrocoll. 2020, 101, 105486. [CrossRef]

27. Ringus, D.L.; Mararu, C.I. Pulsed Light inactivation of Listeria innocua on food packaging materials of different surface roughness and reflectivity. J. Food Eng. 2013, 114, 331-337. [CrossRef]

28. Suganthi, S.; Vignesh, S.; Sundar, J.K.; Raj, V. Fabrication of PVA polymer flms with improved antibacterial activity by fne-tuning via organic acids for food packaging applications. Appl. Water Sci. 2020, 10, 100. [CrossRef]

29. Kaczmarek-Szczepańska, B.; Wekwejt, M.; Mazur, O.; Zasada, L.; Pałubicka, A.; Olewnik-Kruszkowska, E. The Physicochemical and Antibacterial Properties of Chitosan- Based Materials Modified with Phenolic Acids Irradiated by UVC Light. Int. J. Mol. Sci. 2021, 22, 6472. [CrossRef]

30. Sun, L.; Sun, J.; Chen, L.; Niu, P.; Yang, X.; Guo, Y. Preparation and characterization of chitosan film incorporated with thinned young apple polyphenols as an active packaging material. Carbohyd. Polym. 2017, 163, 81-91. [CrossRef]

31. Kosaraju, S.L.; D'ath, L.; Lawrence, A. Preparation and characterisation of chitosan microspheres for antioxidant delivery. Carbohyd. Polym. 2006, 64, 163-167. [CrossRef]

32. Li, K.; Zhu, J.; Guan, G.; Wu, H. Prearation of chitosan-sodium alginate films through layer-by-layer assembly and ferulic acid crosslinking: Film properties, characterization, and formation mechanism. Int. J. Biol. Macromol. 2019, 122, 485-492. [CrossRef] [PubMed]

33. Seah, M.Q.; Lau, W.J.; Goh, P.S.; Tseng, H.H.; Wahab, R.A.; Ismail, A.F. Progress of interfacial polymerization techniques for polyamide thin film (nano)composite membrane fabrication: A comprehensive review. Polymers 2020, 12, 2817. [CrossRef] [PubMed]

34. Schreiber, S.B.; Bozell, J.J.; Hayes, D.G.; Zivanovic, S. Introduction of primary antioxidant activity to chitosan for application as a multifunctional food packaging material. Food Hydrocoll. 2013, 33, 207-214. [CrossRef]

35. Wu, X.; Beecher, G.R.; Holden, J.M.; Haytowitz, D.B.; Gebhardt, S.E.; Prior, R.L. Lipophilic and hydrophilic antioxidant capacities of common foods in the United States. J. Agriculture Food Chem. 2004, 52, 4026-4037. [CrossRef]

36. Wang, Y.; Xie, M.; Ma, G.; Fang, Y.; Yang, W.; Ma, N.; Fang, D.; Hu, Q.; Pei, F. The antioxidant and antimicrobial activities of different phenolic acids grafted onto chitosan. Carbohydr. Polym. 2019, 225, 115328. [CrossRef]

37. Kikuzaki, H.; Hisamoto, M.; Hirose, K.; Akiyama, K.; Taniguchi, H. Antioxidant properties of ferulic acid and its related compounds. J. Agric. Food Chem. 2002, 50, 2161-2168. [CrossRef]

38. Cheng, S.Y.; Wang, B.; Weng, Y.M. Antioxidant and antimicrobial edible zein/chitosan composite films fabricated by incorporation of phenolic compounds and dicarboxylic acids. LWT Food Sci. Technol. 2015, 63, 115-121. [CrossRef]

39. Liu, J.; Liu, S.; Chen, Y.; Zhang, L.; Kan, J.; Jin, C. Physical, mechanical and antioxidant properties of chitosan films grafted with different hydroxybenzoic acids. Food Hydrocoll. 2017, 7, 176-186. [CrossRef] 